\title{
E-HEALTH BERBASIS MOBILE UNTUK MENINGKATKAN LAYANAN KLINIK
}

\author{
Andi Nurkholis ${ }^{1)}$, Eka Saputra ${ }^{2)}$ \\ ${ }^{1}$ Informatika, Universitas Teknokrat Indonesia \\ ${ }^{2}$ Sistem Informasi, Universitas Teknokrat Indonesia \\ ${ }^{1,2}$ Z. A. Pagar Alam, No. 9-11, Labuhan Ratu, Bandar Lampung, Lampung \\ Email: 'andinh@teknokrat.ac.id, ${ }^{2}$ eka.saputra.mhs@mhs.teknokrat.ac.id
}

\begin{abstract}
E-health is a public service consisting of information and communication technology linked to all functional elements that serve the health sector as a knowledge base. Prospective patients must still fill out a registration form to complete the data at the Ngudi Waluyo Clinic, which results in long lines. Furthermore, information about outpatient registration procedures and practicing doctors is difficult to access, and patient medical records are still written in notebooks traditionally. As a result, searching for patient history data will take a long time, and there is no backup of these records, which can cause data loss at any time. This study aims to develop mobile-based e-health to improve clinical services and make it easier for the public to obtain health services. The system was developed using the extreme programming method applied in mobile applications by utilizing PHP as programming language and MySQL as a database and system testing using the ISO 25010 standard. Through e-health, patients can register outpatients anytime and anywhere without queue, improving the quality of service at the Ngudi Waluyo clinic. Based on the testing results on ten respondents, it was found that the developed e-health was feasible to use with a final score of $90.59 \%$.
\end{abstract}

Keyword: clinic, e-health, extreme programming, health service, ISO 25010

\begin{abstract}
Abstrak
E-health adalah layanan publik yang terdiri dari teknologi informasi dan komunikasi yang terkait dengan semua elemen fungsional yang melayani sektor kesehatan sebagai basis pengetahuan. Calon pasien masih harus mengisi formulir pendaftaran untuk melengkapi data di Klinik Ngudi Waluyo, yang menghasilkan antrean panjang. Selain itu, informasi tentang prosedur pendaftaran rawat jalan dan dokter yang berlatih sulit diakses, dan catatan medis pasien masih ditulis di buku catatan secara tradisional. Akibatnya, mencari data riwayat pasien akan memakan waktu lama, dan tidak ada cadangan data, sehingga dapat menyebabkan kehilangan data kapan saja. Penelitian ini bertujuan untuk mengembangkan e-health berbasis mobile untuk meningkatkan layanan klinis dan memudahkan masyarakat untuk mendapatkan layanan kesehatan. Sistem dikembangkan menggunakan metode extreme programming yang diterapkan dalam aplikasi mobile dengan memanfaatkan PHP sebagai bahasa pemrograman dan MySQL sebagai basis data dan pengujian sistem menggunakan standar ISO 25010. Melalui e-health, pasien dapat mendaftarkan pasien rawat jalan kapan saja dan di mana saja tanpa antrian, meningkatkan kualitas layanan di klinik Ngudi Waluyo. Berdasarkan hasil pengujian pada sepuluh responden, ditemukan bahwa e-health yang dikembangkan layak digunakan dengan skor akhir 90.59\%.
\end{abstract}

Kata kunci: e-health, extreme programming, ISO 25010, klinik, layanan kesehatan

\section{Pendahuluan}

Kemajuan teknologi dalam kehidupan manusia tidak dapat dipisahkan [1], terutama ketika berbicara tentang peran internet, yang sangat penting dalam teknologi [2]. Tidak terkecuali, terutama pada kecepatan internet, sangat mempengaruhi kemampuan agensi untuk membangun lebih banyak sistem layanan dengan melibatkan teknologi informasi dan [3] Pengguna internet di Indonesia pada tahun 2014 adalah 87 juta, yang kemudian meningkat menjadi 112 juta pengguna pada tahun 2017 [4]. Dengan demikian, dapat dikatakan bahwa masyarakat telah secara konsisten meningkat dalam menggunakan teknologi.
Klinik Ngudi Waluyo adalah klinik yang memberikan pelayanan kesehatan bagi masyarakat, khususnya wilayah Tanjung Bintang, Provinsi Lampung Selatan. Salah satu layanan kesehatan di Klinik Ngudi Waluyo adalah Poliklinik. Berdasarkan pengamatan, calon pasien sering mengantri di unit pendaftaran untuk mengisi formulir untuk melengkapi data. Selain itu, informasi mengenai prosedur pendaftaran rawat jalan dan dokter praktik belum diakses secara maksimal oleh masyarakat. Selain itu, penulisan rekam medis pasien di klinik juga masih dilakukan secara manual menggunakan buku lembar pasien, sehingga rentan terhadap kehilangan data.

E-health adalah layanan publik dalam bentuk 
aplikasi Teknologi Informasi dan Komunikasi yang terhubung ke semua elemen fungsional yang mendukung sektor kesehatan sebagai basis pengetahuan [5], [6]. Di bidang medis, teknologi telekomunikasi pada awalnya digunakan untuk komunikasi antara pasien dan dokter, layanan sehat, dan pertukaran data kesehatan [7]. E-health dapat diterapkan pada layanan kesehatan yang membuatnya lebih mudah untuk mendapatkan informasi [8]. Layanan kesehatan memiliki persyaratan dasar layanan kesehatan: ketersediaan berkelanjutan, dapat diterima dan masuk akal di masyarakat, mudah dicapai, mudah dijangkau, dan berkualitas baik. Selain itu, layanan kesehatan meliputi pendaftaran, pengumpulan data, pemeriksaan, pengobatan, dan rawat jalan dan rawat inap.

Penelitian sebelumnya mengembangkan desain $e$ health untuk pendaftaran online, pengiriman resep, serta pasien dapat melihat riwayat kesehatan mereka selama perawatan [7], [9]. Selanjutnya, penelitian lainnya yang merupakan hasil sistem konsultasi dokter dan penjualan obat [10]. Model yang diusulkan dapat membantu operasi klinik dan berbagi data, dan penjualan obat. Penelitian lain, mengkaji desain model arsitektur ini, dan dapat membuatnya lebih mudah untuk menentukan model aplikasi sistem informasi kesehatan, bahkan dapat menjadi tolok ukur untuk implementasi di masa depan [3], [11]. Berdasarkan penelitian yang dijelaskan, e-health dapat digunakan sebagai solusi digitalisasi layanan kesehatan yang awalnya konvensional untuk meningkatkan kualitas pelayanan kesehatan yang diberikan kepada masyarakat.

Penelitian ini bertujuan mengembangkan aplikasi $e$ health berbasis mobile untuk meningkatkan pelayanan kesehatan kepada masyarakat dalam memperoleh informasi seputar layanan klinik. Sistem dikembangkan menggunakan metode pemrograman ekstrim yang adaptif dan komunikatif [12], yang mencakup tahap planning, design, coding, dan testing untuk mengakomodasi fungsi yang dibutuhkan dalam layanan kesehatan. Pengembangan sistem dilakukan dengan menggunakan bahasa pemrograman PHP dan basis data MySQL sebagai area penyimpanan data. Sistem diharapkan dapat mempermudah pasien untuk melakukan pendaftaran rawat jalan kapan dan dimana saja tanpa perlu melakukan pengantrian, serta dapat memaksimalkan kinerja pelayanan di Klinik Ngudi Waluyo.

\section{Metode}

Objek pada penelitian ini merupakan Klinik Ngudi Waluyo Lampung Selatan yang membutuhkan solusi khususnya dalam hal pelayanan masyarakat. Dalam pengembangan sistem, digunakan metode extreme programming yang merupakan suatu pendekatan pengembangan perangkat lunak secara cepat [13]. Alasan penggunaan metode extreme programming adalah sifat dari sistem yang hendak dikembangkan secara cepat, meliputi planning, design, coding, dan testing [14]. Secara umum, penelitian ini terdiri dari 6 tahapan, ditunjukkan pada Gambar 1.

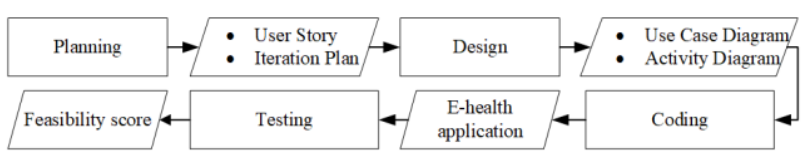

Gambar 1. Tahapan penelitian

Berdasarkan Gambar 1, berikut penjelasannya.

\subsection{Planning}

Pada tahap perencanaan, wawancara dilakukan dengan pengguna untuk menentukan kebutuhan dan fungsi yang akan diimplementasikan dalam sistem. Wawancara dilakukan melalui sesi tanya jawab langsung dengan Staf Klinik Ngudi Waluyo tentang sistem pelayanan yang berjalan. Hasil dari tahap perencanaan adalah user story dan iteration plan.

1. User Story, berdasarkan hasil wawancara yang dilakukan, prosedur pendaftaran poliklinik bagi calon pasien harus datang untuk mengisi formulir pendaftaran yang disediakan untuk melengkapi data, sehingga terjadi penumpukan antrian saat pendaftaran. Selain itu, informasi tentang prosedur pendaftaran rawat jalan dan dokter praktik tidak dapat diperoleh secara optimal, serta rekap medis pasien masih dilakukan secara manual. Berikut ini adalah rencana sistem yang akan dikembangkan untuk memecahkan masalah ini, yang ditunjukkan pada Tabel 1.

Tabel 1. User story

\begin{tabular}{cl}
\hline No & \multicolumn{1}{c}{ Kebutuhan } \\
\hline 1 & $\begin{array}{l}\text { Sistem bersifat user friendly sehingga mudah } \\
\text { bagi pengguna untuk menggunakan }\end{array}$ \\
2 & $\begin{array}{l}\text { Sistem perlu menampilkan informasi tentang } \\
\text { klinik }\end{array}$ \\
3 & $\begin{array}{l}\text { Sistem perlu menyediakan layanan input untuk } \\
\text { data dokter, data kamar, jadwal alur prosedur } \\
\text { layanan }\end{array}$ \\
4 & $\begin{array}{l}\text { Sistem perlu menghasilkan statistik pengunjung } \\
\text { berdasarkan dokter dan penyakit. }\end{array}$ \\
\hline
\end{tabular}

2. Iteration Plan, berdasarkan durasi sistem, perencanaan iterasi diperlukan dengan mempertimbangkan user story pengguna yang telah ditentukan sebelumnya. Berikut ini adalah iteration plan yang ditunjukkan pada Gambar 2.
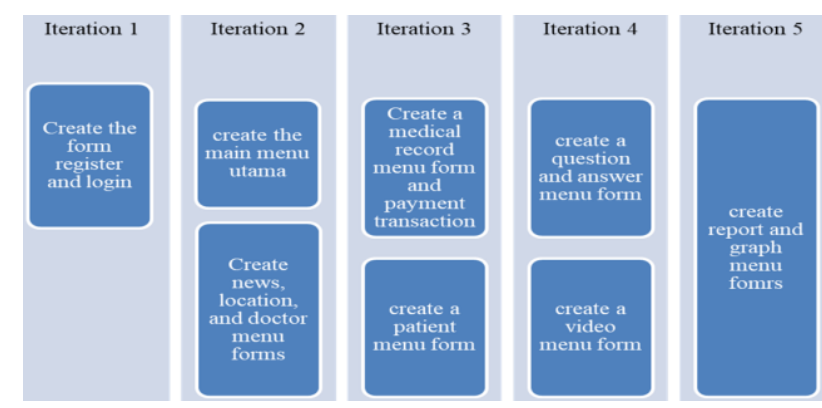

Gambar 2. Iteration plan 


\subsection{Design}

Dalam pengembangan perangkat lunak, desain proses bisnis berusaha untuk membangun sistem yang memenuhi spesifikasi kebutuhan [15], [16] Tahap ini berfungsi untuk membuat spesifikasi mengenai arsitektur program, antarmuka, dan elemen pendukung. Fase desain divisualisasikan dalam penggunaan diagram kasus dan diagram aktivitas menggunakan Perangkat Lunak Astahcomunity. Berdasarkan analisis yang telah dilakukan, kami memperoleh apa yang dibutuhkan oleh pengguna untuk aplikasi e-health. Desain use case diagram dan activity diagram secara berurutan ditunjukkan pada Gambar 3 dan Gambar 4.

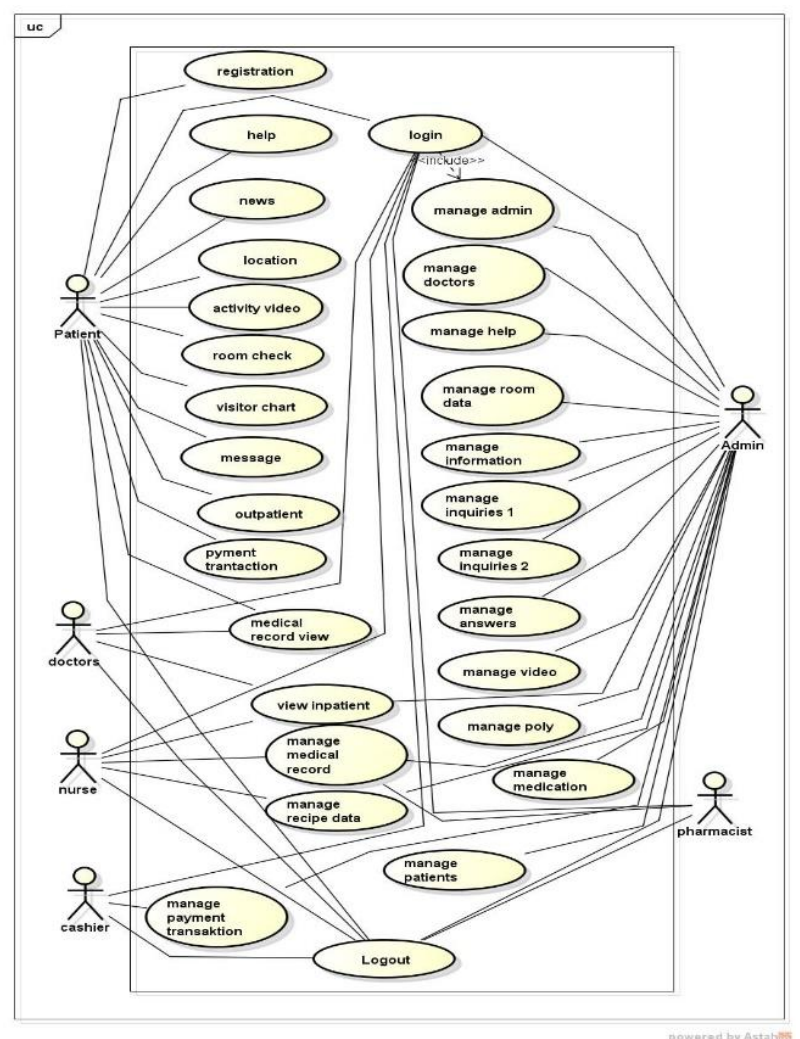

Gambar 3. Use case diagram

Berdasarkan use case diagram pada Gambar 3, pengguna terdiri dari lima aktor, yaitu admin, pasien, dokter, perawat, dan kasir, yang memiliki hak akses. Admin mengelola data penting seperti data admin, dokter, informasi, instruksi, kamar, pasien, dan poli. Pasien dapat mendaftarkan pasien rawat jalan dan melihat informasi, instruksi, dan catatan medis saat merawat pasien. Dokter memiliki hak akses untuk melihat catatan medis dan informasi rawat jalan pasien. Perawat dapat melihat informasi rawat jalan dan mengelola catatan medis pasien. Kasir bertanggung jawab untuk mengelola transaksi pembayaran. Alur proses dari masing-masing pengguna kemudian digambarkan melalui activity diagram yang ditunjukkan pada Gambar 4.

\subsection{Coding}

Pada tahap ini digunakan Adobe Dreamweaver untuk merancang aplikasi $e$-health berbasis mobile. PHP adalah bahasa pemrograman yang digunakan untuk membangun sistem berbasis mobile. Basis data MySQL dan framework bootstrap juga diperlukan untuk pengembangan sistem ini. Masing-masing komponen dijelaskan secara lebih rinci sebagai berikut:

1. PHP digunakan sebagai backend untuk mengintegrasikan basis data dan antarmuka pengguna.

2. Basis data MySQL digunakan sebagai penyimpanan data.

3. Bootstrap digunakan sebagai framework antarmuka yang menarik dan interaktif.

\subsection{Testing}

Pada tahap akhi, sistem dilakukan pengujian menggunakan metode ISO 25010 pada aspek functional suitability, usability, dan performance efficiency [17]. Tiga dari delapan aspek dipilih sesuai dengan kebutuhan aplikasi yang diinginkan [18]. Rumus untuk menghitung persentase pengujian dalam Persamaan 1 adalah sebagai berikut [14].

$$
\text { Testing }(\%)=\frac{\text { Actual score }}{\text { Ideal score }} \times 100
$$

Actual score adalah jawaban seluruh responden atas kuesioner yang telah diajukan, sedangkan ideal score merupakan nilai tertinggi atau semua responden diasumsikan memilih jawaban dengan skor tertinggi. Hasil uji kemudian dihitung menggunakan Persamaan 1, dan dilanjutkan oleh interpretasi berbasis skala Likert untuk menilai kelayakan sistem. Kriteria interpretasi dapat dillihat pada Tabel 2 [19].

Tabel 2. Skor kriteria interpretasi

\begin{tabular}{ll} 
Rentang (\%) & \multicolumn{1}{c}{ Penilaian } \\
\hline $0-20$ & Very poor \\
$21-40$ & Poor \\
$41-60$ & Slightly not good \\
$61-80$ & Good \\
$81-100$ & Very good \\
\hline
\end{tabular}




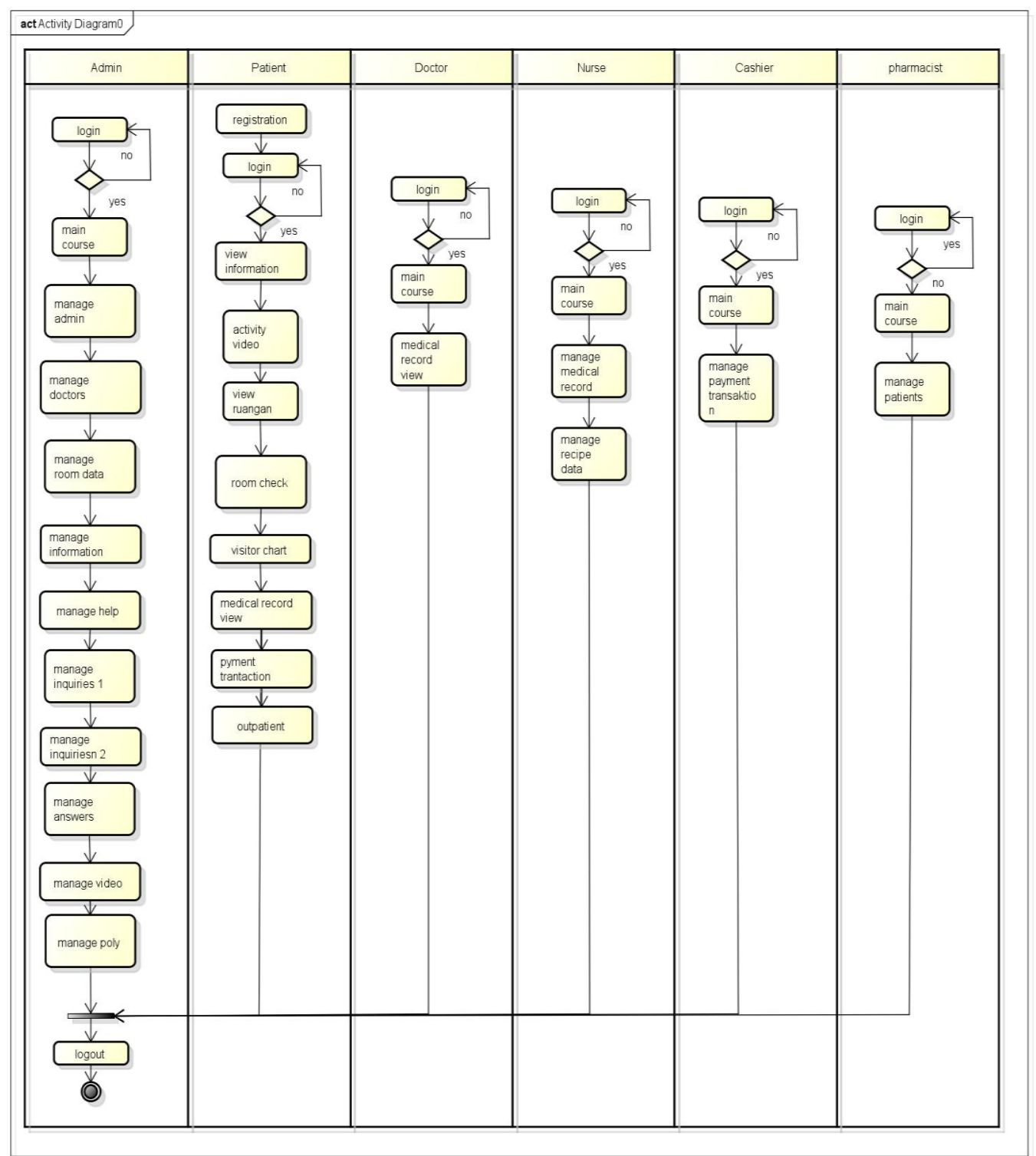

Gambar 4. Activity diagram

\section{Hasil dan Diskusi}

\subsection{E-health Berbasis mobile}

Contoh tampilan sistem yang telah dikembangkan adalah sebagai berikut:

1. Menu utama adalah tampilan awal aplikasi e-health. Ada link ke menu lain dalam menu ini, seperti bantuan, berita, jadwal dokter, lokasi, kegiatan video, ruang pemeriksaan, grafik statistik, obrolan pintar, rawat jalan, catatan medis, dan riwayat transaksi. Berikut ini adalah menu utama yang dapat dilihat pada Gambar 5.

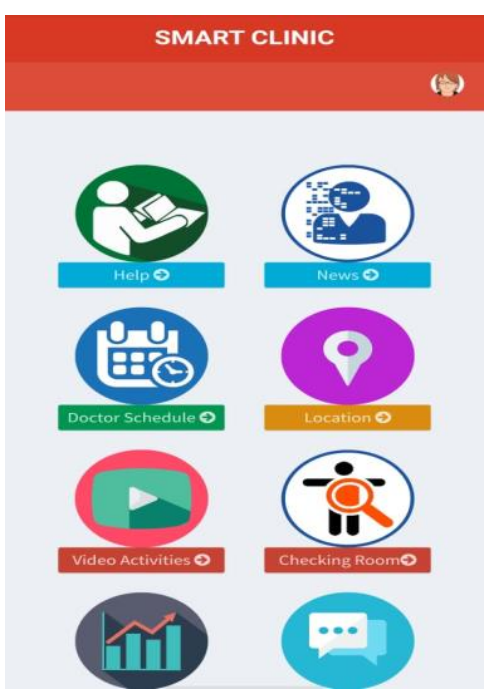

Gambar 5. Menu utama 
2. Doctor schedule adalah menu yang menampilkan jadwal dokter untuk aktivitas dokter di klinik. Ada informasi tentang jadwal dokter di klinik yang telah dimasukkan admin dalam menu ini. Berikut adalah menu doctor schedule yang ditunjukkan pada Gambar 6.

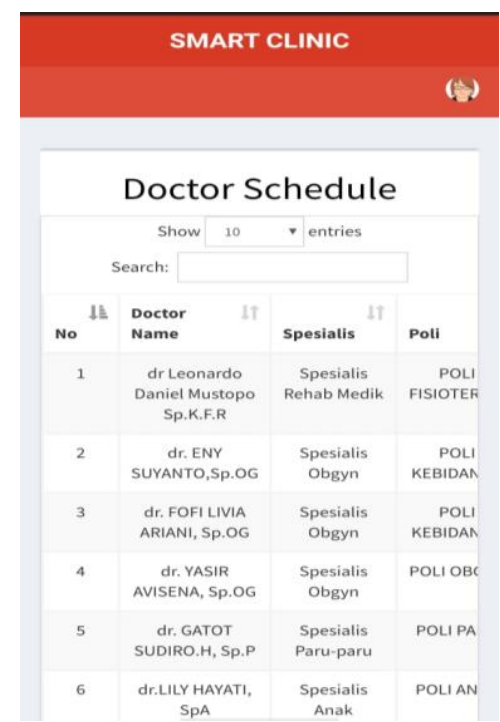

Gambar 6. Menu doctor schedule

3. Smart chat adalah menu yang menyediakan fasilitas percakapan real-time kepada admin (staf klinik) sehingga akan lebih mudah bagi pengguna jika mengalami kendala. Berikut ini adalah menu smart chat yang bisa dilihat pada Gambar 7.

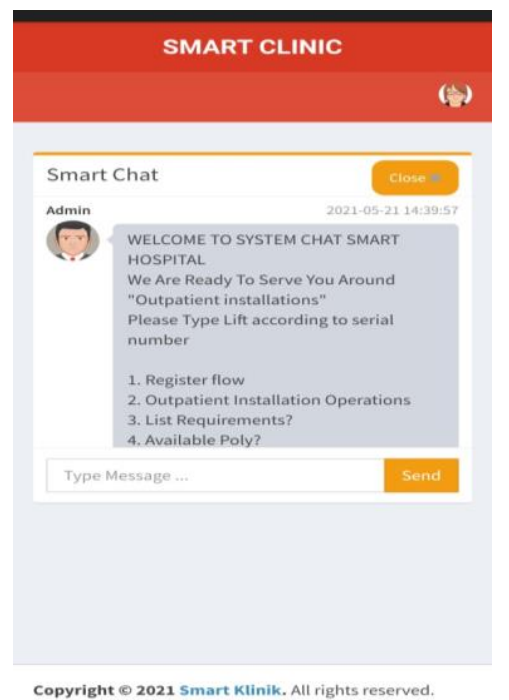

Gambar 7. Menu smart chat

4. Outpatient adalah menu untuk melihat data rawat jalan pasien. Menu ini menampilkan informasi mengenai hasil ID, poly, date, dan medical record sehingga pasien dapat melihat riwayat pengobatan yang telah dilakukan. Berikut ini adalah menu outpatient yang ditunjukkan pada Gambar 8.

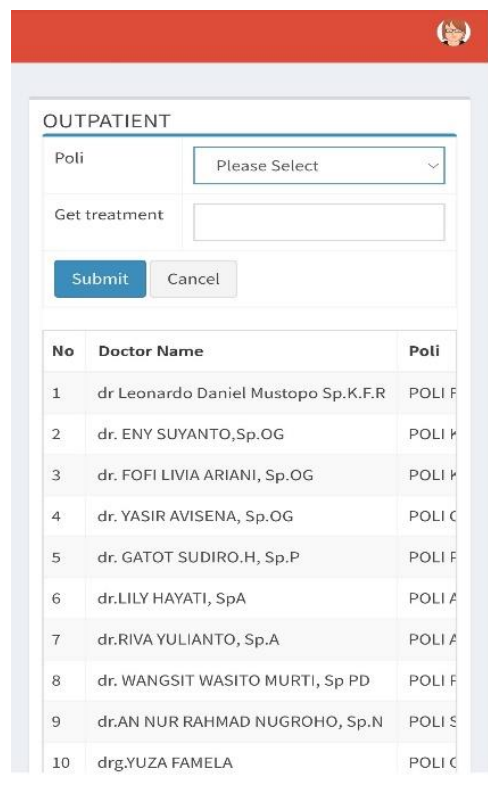

Gambar 8. Menu outpatient

5. Medical record adalah menu untuk melihat data rekam medis pasien. Menu ini akan menampilkan hasil kegiatan perawatan pasien. Berikut ini adalah menu medical record yang dapat dilihat pada Gambar 9.

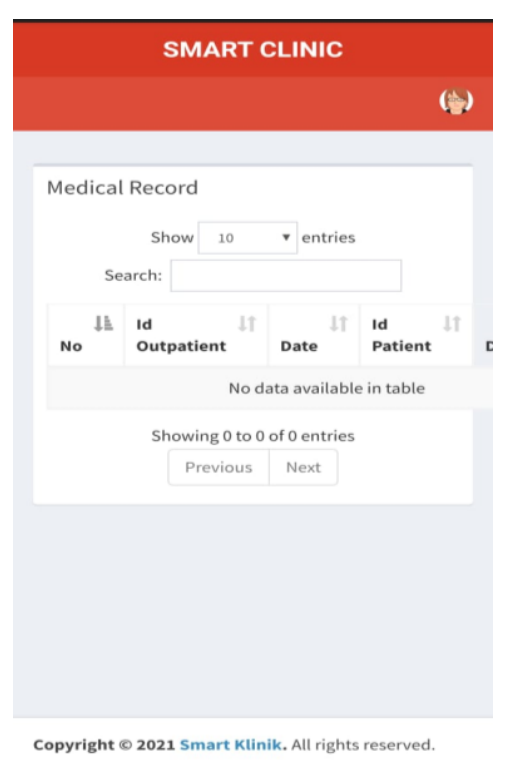

Gambar 9. Menu medical record

\subsection{Pengujian ISO 25010}

Sistem yang dikembangkan ini diuji melibatkan 10 responden yang terdiri dari lima pelanggan dan lima staf Klinik Ngudi Waluyo. Berikut adalah rincian hasil ujinya.

1. Functional suitability dilakukan untuk menentukan kemampuan fungsionalitas dalam melakukan tugastugas tertentu bagi pengguna dan untuk memberikan hasil dan akurasi yang tepat dalam menanggapi permintaan pengguna. Pengujian functional suitability dilakukan melalui kuesioner yang berisikan 10 pertanyaan kepada 10 responden. Berikut adalah hasil perhitungan nilai bobot 
keseluruhan responden untuk aspek functional suitability.

$$
\frac{466}{500} \times 100 \%=93.2 \%
$$

Hasil pengujian kualitas perangkat lunak pada aspek functional suitability memperoleh persentase keberhasilan sebesar 93.2\%. Nilai yang diperoleh tersebut selanjutnya dikonversi berdasarkan skala Likert pada Tabel 2. Hasil persentase yang dicapai menunjukkan bahwa kualitas sistem pada aspek functional suitability adalah Very Good.

2. Usability dilakukan untuk melihat kemudahan bagi pengguna untuk menggunakan dan mengoperasikan sistem. Pengujian usability dilakukan melalui kuesioner yang berisikan 13 pertanyaan kepada 10 responden. Berikut adalah hasil perhitungan nilai bobot keseluruhan responden untuk aspek usability.

$$
\frac{576}{650} \times 100 \%=88.62 \%
$$

Hasil pengujian kualitas perangkat lunak pada aspek usability memperoleh persentase keberhasilan sebesar $88.62 \%$. Nilai yang diperoleh tersebut selanjutnya dikonversi berdasarkan skala Likert pada Tabel 2. Hasil persentase yang dicapai menunjukkan bahwa kualitas sistem pada aspek usability adalah Good.

3. Performance efficiency dilakukan untuk mengetahui berapa banyak waktu dan sumber daya yang diperlukan untuk menyelesaikan suatu kegiatan dari fungsi dalam program. Pengujian performance efficiency dilakukan melalui kuesioner yang berisikan 4 pertanyaan kepada 10 responden. Berikut adalah hasil perhitungan nilai bobot keseluruhan responden untuk aspek performance efficiency.

$$
\frac{181}{200} \times 100 \%=90.5 \%
$$

Hasil pengujian kualitas perangkat lunak pada aspek performance efficiency memperoleh persentase keberhasilan sebesar $90.5 \%$. Nilai yang diperoleh tersebut selanjutnya dikonversi berdasarkan skala Likert pada Tabel 2. Hasil persentase yang dicapai menunjukkan bahwa kualitas sistem pada aspek performance efficiency adalah Very Good.

Berikut adalah hasil keseluruhan pengujian ISO 25010 yang mencakup tiga aspek: functional suitability, usability, dan performance efficiency.

$$
\frac{1223}{1350} \times 100 \%=90.59 \%
$$

Berdasarkan hasil pengujian ISO 25010 terhadap sepuluh responden diperoleh skor $90.59 \%$, sehingga sistem dapat diinterpretasikan dengan skala Very Good, serta dianggap layak untuk diterapkan pada Klinik Ngudi Waluyo.

\section{Kesimpulan}

Penelitian ini telah berhasil mengembangkan aplikasi $e$-health sebagai digitalisasi pelayanan kesehatan, khususnya rawat jalan, sehingga mempermudah pasien untuk melakukan berobat jalan. Selain itu, dalam aplikasi juga disediakan fasilitas chat untuk meningkatkan pelayanan di Klinik Ngudi Waluyo. Pengembangan sistem dilakukan menggunakan metode extreme programming yang mencakup planning, design, coding, dan testing. Hasil pengujian ISO 25010 yang telah dilakukan dengan melibatkan 10 Responden bahwa kesimpulan kualitas kelayakan perangkat lunak dengan skor $90.59 \%$ yang dihasilkan secara keseluruhan mempunyai skala "Very Good".

\section{Daftar Pustaka}

A. Nurkholis, A. Riyantomo, and M. Tafrikan, "Sistem Pakar Penyakit Lambung Menggunakan Metode Forward Chaining," Momentum, vol. 13, no. $1, \quad$ p. $32-38, \quad 2017$, doi: 10.36499/jim.v13i1.1757.

[2] I. S. Sitanggang, A. Nurkholis, Annisa, and M. A. Agmalaro, "Garlic Land Suitability System based on Spatial Decision Tree," in Proceedings ofthe International Conferences on Information System and Technology, 2020, no. CONRIST 2019, pp. 206-210, doi: 10.5220/0009908002060210.

[3] J. H. Sambuaga and Y. D. Y. Rindengan, "Perancangan E-health Kota Cerdas (Studi Kasus: Kota Manado)," J. Tek. Inform., vol. 11, no. 1, 2017.

[4] S. Sudaryat, D. E. Sukarsa, and A. M. Ramli, "PERLINDUNGAN KEKAYAAN INTELEKTUAL KARYA KREATIF DAN INOVATIF BISNIS STARTUP DI INDONESIA DALAM ERA INDUSTRI 4.0 DAN SOCIETY 5.0," ACTA DIURNAL J. Ilmu Huk. Kenotariatan, vol. 4, no. 1, pp. 68-82, 2020.

[5] T. H. Tebeje and J. Klein, "Applications of $e$ health to support person-centered health care at the time of COVID-19 Pandemic," Telemed. ehealth, vol. 27, no. 2, pp. 150-158, 2021.

[6] A. Muzakir, "Prototyping Aplikasi E-health sebagai Bagian Pengenalan Obat-Obatan Dengan Teknologi Cross-Platform," J. Inform. J. Pengemb. IT, vol. 3, no. 1, pp. 61-66, 2018.

[7] P. W. Sudarmadji, Y. S. Peli, and L. A. Ndoloe, " $E$ health (Electronic Health) Solution Puskesmas Untuk Menentukan Status Kesehatan Ibu dan Anak," J. Ilm. Flash, vol. 4, no. 1, pp. 24-36, 2018.

D. Prasanti and S. S. Indriani, "PENGEMBANGAN TEKNOLOGI INFORMASI DAN KOMUNIKASI DALAM SISTEM E-HEALTH 'alodokter. com,"' $J$. 
Sosioteknologi, vol. 17, no. 1, pp. 93-103, 2018.

[9] M. Purnamasari and S. Dwiyatno, "Rancang Bangun Aplikasi e-health Untuk Peningkatkan Pelayanan Kesehatan Pada Puskesmas Kibin," JSiI (Jurnal Sist. Informasi), vol. 3, 2016.

[10] N. Riyani, J. T. Napitupulu, and W. Manurian, "PEMODELAN E-HEALTH PADA KLINIK UNTUK PROSES KONSULTASI DOKTER DAN PENJUALAN OBAT," in PROSIDING SEMINAR NASIONAL ENERGI \& TEKNOLOGI (SINERGI), 2019, pp. 121-130.

[11] W. A. Setianto, "Inovasi e-health Dinas Kesehatan Kota Surabaya," J. Ilmu Komun., vol. 14, no. 3, pp. 151-164, 2016.

[12] L. Sadath, K. Karim, and S. Gill, "Extreme programming implementation in academia for software engineering sustainability," $2018 \mathrm{Adv}$. Sci. Eng. Technol. Int. Conf. ASET 2018, no. December, pp. 1-6, 2018, doi: 10.1109/ICASET.2018.8376925.

[13] R. Poonam and C. M. Yasser, "An experimental study to investigate personality traits on pair programming efficiency in extreme programming," in 2018 5th International Conference on Industrial Engineering and Applications (ICIEA), 2018, pp. 95-99.

[14] A. Nurkholis, E. R. Susanto, and S. Wijaya, "Penerapan Extreme Programming dalam
Pengembangan Sistem Informasi Manajemen Pelayanan Publik," J-SAKTI (Jurnal Sains Komput. dan Inform., vol. 5, no. 1, pp. 124-134, 2021, doi: 10.30645/j-sakti.v5i1.304.

[15] D. Dakic, D. Stefanovic, T. Lolic, S. Sladojevic, and A. Anderla, "Production planning business process modelling using UML class diagram," in 2018 17th international symposium infotehjahorina (infoteh), 2018, pp. 1-6.

[16] M. H. Karboos, "Integrating Business Process Concepts Into UML Activity Model," J. Eng. Comput. Sci., vol. 19, no. 1, pp. 57-68, 2019.

[17] ISO, "ISO / IEC 25010: 2011 Systems and software engineering - Systems and software Quality Requirements and Evaluation ( SQuaRE) - System and software quality models," 2013.

[18] F. Rozi and K. Khomsatun, "Rancang bangun game edukasi pengenalan warna untuk pendidikan anak usia dini menggunakan adobe flash berbasis android," J. Ilm. Penelit. dan Pembelajaran Infromatika, vol. 04, pp. 12-18, 2019.

[19] Z. Awang, A. Afthanorhan, and M. Mamat, "The Likert scale analysis using parametric based Structural Equation Modeling (SEM)," Comput. Methods Soc. Sci., vol. 4, no. 1, p. 13, 2016. 